\title{
Matar a Sócrates: los pensamientos tardíos de Platón acerca de la democracia ${ }^{1}$
}

\section{Christopher Rowe}

is preocupaciones presentes radican en tratar de entender a Platón como escritor de filosofía, y en el modo como debemos leer los diálogos. Ya sea como dato inicial o bien, más usualmente, como conclusión de un argumento, considero que hay, no sólo maneras erróneas de leer a Platón, sino también, en términos generales, una forma correcta de leerlo, que podemos descubrir -o con mayor frecuencia, a la cual podemos acercarnos- sobre la base de lo que él mismo escribió. En todo caso, a lo largo de la historia Platón no sólo ha sido leído de maneras muy distintas, sino que muchos diálogos y muchos contextos singulares en los diálogos parecen ser fundamentalmente diferentes en uno o más de una serie de aspectos: por su contenido filosófico, su método, su humor o su tono -lo cual, por supuesto, es una de las razones de que haya tal variedad en las interpretaciones disponibles, según que los diferentes lectores privilegien distintas partes o aspectos del corpus. Y tampoco es ésta una cuestión meramente frívola o marginal. Por una parte, Platón ha sido visto (como al parecer lo fue por sus sucesores inmediatos en la Academia, o por los neoplatónicos) como el autor y proponente de sistemas metafísicos más o menos grandiosos. Pero también, para otros, antiguos y modernos, es un escéptico que, como era de esperarse -y hablando con un tono de voz apropiadamente escéptico- se rehúsa en definitiva a comprometerse a sí mismo con cualquier cosa, o no logra hallar ningún fundamento para hacerlo. Mi interés escencial consiste en intentar mediar en este tipo de disputa, en particular en su forma moderna. El primer paso es tratar de poner al descubier-

\footnotetext{
${ }^{1}$ Este escrito, o una versión anterior, fue leído por primera vez en un Coloquio de Filosofía en la Universidad de Wisconsin-Madison; después, en el Center for Hellenic Studies, Washington, D. C., la Southern Association for Ancient Philosophy (Oxford, Reino Unido) y la Universidad de Utrecht. Agradezco los comentarios y las sugerencias que recibí del público en las tres ocasiones.
} 
to las capas de supuestos y prejuicios que, típicamente, introducimos en la lectura de Platón, y el presente artículo forma parte de este proyecto particular. Un segundo punto de partida es que, si la historia de la filosofía importa, entonces importa aclarar bien qué significaron y de qué se ocuparon las figuras particulares en esa historia; y un tercer punto de partida es que el estudio de la historia de la filosofía sí importa. Pero si se me pidiera justificar esta última afirmación, con seguridad formularía mi respuesta, al menos en parte, en términos cualitativos; dentro de un contexto filosófico (en contraste con uno histórico o el de un anticuario), el desahogo y la facilidad de la defensa aumentará en proporción directa a la calidad de la inteligencia, las ideas y los argumentos que el estudio vaya revelando. En esta oportunidad, espero demostrar por qué debemos oponernos a una clase particular de interpretación, la cual comprometería -y de hecho pone en grave riesgo- el justo derecho de Platón a ser objeto de una consideración seria. Hasta donde puedo ver, la clase de interpretación que tengo en mente implica que, hacia el final de su vida, Platón se habría desecho de la mayor parte de aquello en que antes había creído, en cuya defensa había empleado mucho tiempo, esfuerzo y pasión. Y lo que es más importante: de manera más o menos abierta habría rechazado esa preocupación por la virtud humana y la búsqueda de la felicidad que asociamos característicamente con él -y con su maestro Sócrates.

A la vez, también me interesa rechazar el tipo de enfoque de Platón que subyace en la interpretación específica que deseo remplazar. La mayoría de los intérpretes contemporáneos de Platón comienzan por asumir que su pensamiento se desarrolló a lo largo de su vida, lo cual es en sí mismo, quizás, algo inocuo. Pero luego proceden a dar por descontado que este desarrollo o evolución es uno de los factores principales, quizás incluso el factor más importante, detrás de las diferencias aparentes entre las ideas que él ofrece a lo largo de los diálogos. De este modo, es normal iniciar cualquier introducción a Platón mediante una división de sus diálogos en "tempranos", "intermedios" y "tardíos", y caracterizar el pensamiento de estos tres "periodos" en ciertas formas estandarizadas. Así, "temprano" equivale aproximadamente a "socrático"; "intermedio" es "constructivo" u "optimista" (o, de modo alternativo, el periodo en que Platón se excedió), en tanto que "tardío" es "crítico" o "pesimista", o bien, cuando Platón abandonó los excesos platonistas de la fase intermedia y comenzó a hacer filosofía de veras. Los rasgos característicos de diálogos individuales de cada grupo son entonces explicados de acuerdo con este esquema. Ésta es la clase de aproximación que deseo objetar. Sería por supuesto absurdo oponerse por completo a admitir la posibilidad de que el pensamiento de Platón haya evolucionado o cambiado; mi propuesta es simplemente que este tipo de explicación debiera emplearse 
sólo como último recurso, porque depende de suposiciones acerca de su estado de ánimo y de su biografía en general, a los cuales tenemos muy poco o ningún acceso. El punto fundamental -aunque con frecuencia es olvidado- es que, al interpretar a los filósofos, debiéramos comenzar por tomar en serio sus argumentos, y traer a colación otros factores -esto es, para explicar los argumentos mismos $-{ }^{2}$ sólo si todo lo demás fracasa.

En este artículo examinaré y criticaré un ejemplo especialmente notable, e importante, de esa lectura "desarrollista" del corpus platónico. El texto que estará en el centro del presente trabajo será el Político (o "Estadista"), una de las obras menos leídas y menos amadas de Platón. En exposiciones modernas de la filosofía política platónica, el Político ocupa una posición a medio camino entre la República, del periodo "intermedio", y las tardías Leyes, que es también donde las hipótesis de los estilometristas lo han situado en términos cronológicos. En las Leyes, de acuerdo con la interpretación más común, Platón renuncia a la idea central de la República (central en la medida en que vemos a la República como una obra de filosofía política): en Magnesia, la ciudad de las Leyes, los filósofos-reyes ya no gobiernan (aunque, de hecho, según la datación común, en realidad han dejado de gobernar desde TimeoCritias). Han cedido su lugar a una ley impersonal, que es lo más cerca que podemos llegar en el mundo real al gobierno de la razón. Es el Político, según la explicación usual, el que -situado como está entre las dos obras maestras- proporciona el respaldo teórico a este cambio de perspectiva.

Tal cambio puede ser descrito de muchas y muy distintas maneras, tanto positivas como negativas. Es la prueba principal para aquellos que acusan al viejo Platón de pesimista: después de todo, en las Leyes, él mismo describe la soberanía de la ley como lo "segundo mejor", o algo que ha de ser "elegido en segundo lugar" (dio to deuteron haireteon, taxin te kai nomon, 875d). Platón hubiera preferido la visión gloriosa del gobierno directo de la razón, pero se da cuenta de que tiene que conformarse con menos. Otros describen esto como realismo: un realismo producto de la vejez y la experiencia. Una estrategia más, a menudo combinada con lo anterior, consiste en afirmar que se trata del desarrollo gradual, en la conciencia platónica, de la importancia del constitucionalismo: ${ }^{3}$ en el mundo real, lo que necesitamos es la sólida base provista por la ley, con todo y sus imperfecciones. Y finalmente, el cambio ha sido considerado como un giro hacia una mayor apreciación - por muy renuente que fuera- del valor de la democracia, pues el

${ }^{2}$ Las premisas de los argumentos, naturalmente, son cosa distinta.

${ }^{3}$ Véase por ejemplo C. Gill, "Rethinking Constitutionalism in Statesman 291-303", en C. J. Rowe, ed., Reading the Statesman. Sankt Augustin, 1995. Proceedings of the III Symposium Platonicum. 
Extranjero de Atenas, quien conduce la conversación en las Leyes, muestra que cualquier constitución digna de este nombre tiene que combinar rasgos de la monarquía con características de la democracia. ${ }^{4}$ Estamos, pues, según parece, muy lejos de la República, y de su repudio de la democracia como algo que está a un solo paso de la enfermedad terminal de la ciudad: la tiranía. En el presente artículo me concentraré en esta manera de ver las cosas -es decir, en la tesis de que el Político manifiesta una revaloración, por parte de Platón, de los méritos de la democracia.

El pequeño diálogo Menéxeno muestra a Sócrates ensayando para su joven amigo (Menéxeno) un discurso en alabanza de aquellos atenienses que han muerto por su ciudad. Sócrates ha memorizado ese discurso; Aspasia, compañera y madre de los hijos de Pericles, lo compuso, en parte improvisando y en parte empleando trozos y retazos del más célebre discurso fúnebre que Pericles mismo pronunció, y que ella -según nos dice Sócrates- de hecho escribió. Esta nueva creación de Aspasia consiste, como ocurría con los discursos funerarios, no sólo en el elogio de los muertos, sino en el elogio de la ciudad; y, entre otras cosas que Platón pone en boca de Sócrates, está que la Atenas democrática es en realidad una "aristocracia con la aprobación de la mayoría” (met'eudoxias plêthous aristokratia, 238d), en la medida en que el pueblo soberano eligió a los mejores para gobernar a todos. La mayor parte de los lectores - esto es, la mayor parte de los que consideran el diálogo como auténtico- han considerado al Menéxeno como una parodia platónica. Pero algunos de los antiguos creyeron que era una obra seria, e incluso Cicerón registró (en forma extraordinaria) que, de hecho, al menos en su tiempo, el discurso era recitado anualmente como parte de las actividades con que la ciudad honraba a sus muertos: ${ }^{5}$ si este reporte es fidedigno (y no tenemos ninguna razón para dudarlo, excepto su rareza), la tradición del discurso fúnebre se tornó inoperante en forma paradójica. Pamela $\mathrm{Huby}^{6}$ interpreta el diálogo en parte como una obra satírica y en parte como contribución a un debate acerca de un tema candente de la práctica política en los años ochentas del siglo IV a. C., que tiene algo en común con debates actuales acerca de la beneficencia pública: si la ciudad podía permitirse seguir cuidando a los hijos de quienes murieron defendiéndola. Charles Kahn también se inclina a tomar el Menéxeno en serio, pero de un modo diferente. ${ }^{7}$

${ }^{4}$ Leyes, 693d y ss. Esta última perspectiva, a juzgar por los participantes en el Symposium acerca del Político (véase nota 3), está probablemente cerca de ser la norma; puede combinarse con una o más de las tres anteriores.

${ }^{5}$ Orator, 151.

${ }^{6}$ Phronesis, 2 (1957), pp. 104-114.

${ }^{7}$ Classical Philology, 57 (1963), pp. 220-234. 
Que este diálogo sea enteramente serio es, sin duda, imposible. En particular, no puede ser que Platón sugiera en serio que la democracia ateniense sea en verdad una aristocracia, basándose en que el pueblo escoge a los mejores hombres como gobernantes, o siquiera en que escoge a sus gobernantes. ¿Qué sabe el pueblo? - preguntaría Platón. De acuerdo con la República, los ciudadanos son simplemente incapaces de cualquier discernimiento en materia de política, excepto quizás el de que es mejor para ellos no ser gobernados por sí mismos, sino por alguien más; y el Político conviene claramente en que la totalidad del pueblo es incapaz de adquirir auténtico conocimiento acerca de cualquier cosa, y mucho menos acerca de lo más importante de todo, la dirección y el gobierno de la ciudad. Y sin embargo, como veremos, según la interpretación usual del Político, Platón llega a admitir -aunque sea con renuencia- que un gobierno basado en un menor o mayor grado de ignorancia, combinada con experiencia, es lo máximo a que podemos aspirar. Si fuéramos a trabajarlo en orden cronológico, podríamos considerar el intento de tratar el propio Menéxeno como muestra de una reaproximación, recién hallada por Platón, a un sistema de gobierno que había despreciado durante los años tempranos y maduros de su vida -en cuyo caso, el diálogo no sería ya una parodia, o no sería más que levemente irónico. Desde luego que Platón tenía buenas razones para despreciar a la Atenas democrática, que había condenado y ejecutado a Sócrates. Pero, otra vez, según una interpretación muy familiar, Platón mismo lo traicionó al final. Estoy pensando aquí en el ataque de Popper a Platón en La sociedad abierta y sus enemigos* (así, por ejemplo, "Platón trató de implicar a Sócrates en su grandioso intento de construir la teoría de la sociedad detenida; y no tuvo dificultades para conseguirlo, pues Sócrates ya estaba muerto"). ${ }^{8}$ En todo caso -independientemente de cuáles sean nuestros sentimientos acerca de los términos específicos del ataque de Popper- es sin duda tentador ver al Platón tardío proponiéndose, en forma deliberada, excluir justo esa clase de compromiso con el descubrimiento, o al menos con la búsqueda,

* N. del trad. La traducción de los pasajes de autores - recientes y antiguos, incluido Platón- citados por C. J. Rowe se hizo directamente sobre el texto del artículo original en inglés, cotejando además, en el caso del pasaje que es el centro de gravedad de este artículo, con el texto del Político en griego, añadiendo en ocasiones (entre corchetes) la transliteración de la expresión platónica correspondiente, en favor de la claridad.

${ }^{8}$ The Open Society and Its Enemies, vol. I: The Spell of Plato. 2a. ed. Londres, 1952, p. 194. La crítica de Popper a Platón no sería hoy aceptada en todos sus detalles por la mayoría; sin embargo, en sus términos generales, sigue siendo extraordinariamente influyente (no son muchos, creo, los que se resistirían a atribuir a Platón tendencias totalitarias - a pesar de lo cual, yo mismo considero que las bases de tal atribución son bastante débiles). 
de la verdad, que Sócrates suele representar, de modo característico y justificable. Sólo ocurriría que, paradójicamente (es decir, paradójicamente de acuerdo con el juicio de Popper), ello se combinaría con una nueva disposición para cohabitar con la democracia.

Como lo sugiere mi título, me concentraré en esa caracterización del pensamiento político tardío de Platón, según la cual éste sería al menos más benévolo con la democracia (aunque el asunto de su supuesta "traición" a Sócrates seguirá reapareciendo). El tipo de postura a que intento oponerme queda resumido -de modo admirable- en el siguiente pasaje de G. H. Sabine que describe el Político:

Por primera vez Platón identifica dos tipos de democracia: una forma moderada y una extrema. De manera todavía más notable, ahora hace de la democracia el mejor de los Estados carentes de ley, a pesar de ser [también] el peor de los Estados que observan la ley. ${ }^{9}$ Ambas formas de la democracia son, por ende, mejores que la oligarquía. Evidentemente, Platón se ha acercado a la postura que adoptaría luego, en las Leyes, donde el segundo mejor [Estado] ${ }^{10}$ es descrito como un intento de combinar monarquía y democracia. Ésta es una admisión tácita de que, en el Estado real, los factores de la aprobación y la participación populares no pueden ser pasados por alto. La nueva teoría de Platón, entonces, ha de ser abiertamente la segunda mejor, ya que involucra el poco satisfactorio contraste de la ciudad celestial con la terrena. El caudal disponible de la inteligencia humana no basta para convertir al filósofo-rey siquiera en una posibilidad. Por lo tanto, humanamente, la mejor solución es apoyarse en esa sabiduría que puede encarnar la ley, y en la devoción natural de los hombres hacia la sapiencia del uso y la costumbre. La amargura con que Platón acepta esta componenda es evidente en la ironía con que hace la observación de que ahora debe justificarse la ejecución de Sócrates. El Estado, con su ley heredada, debe ser concebido como una suerte de imitación de la ciudad celestial. ${ }^{11}$

${ }^{9}$ El Político identifica tres tipos generales (aquellos [Estados] gobernados por una persona, aquellos gobernados por unos pocos, y aquellos gobernados por muchos) divididos en dos (obedientes de la ley o sujetos por la ley, y sin ley).

${ }^{10}$ Es decir, el mejor de los Estados factibles.

${ }^{11}$ G. H. Sabine, A History of Political Theory. 3a. ed. Nueva York, 1961, p. 75. Cf. también J. Annas y R. Waterfield, eds., Plato: Statesman. Cambridge, Cambridge Texts in the History of Political Thought, 1995, pp. XVIII-XX. 
Este pasaje de Sabine proporciona también una explicación del título principal de este trabajo: 'Matar a Sócrates'. Si el Político de veras nos dice, o sugiere, que el gobierno ideal de un solo individuo bien provisto de sabiduría (a grandes rasgos, el 'filósofo-rey' de Sabine) es una imposibilidad, o al menos algo improbable, seguramente deberemos conformarnos con lo segundo mejor; y esto, según la usual, moderna perspectiva del Político, que Sabine refleja, es alguna forma de gobierno - de una sola persona, unos pocos, o la mayoría- que exige un apego absoluto a la ley, ${ }^{12}$ e implicaría en realidad convertir la investigación de la verdad en un delito capital, sobre la base de que "nada debe ser más sabio que la ley". ${ }^{13}$ La mayoría de los otros intérpretes han preferido no admitir esta consecuencia, pero a mí me parece que es bastante real: según su lectura, la implicación del texto de Platón es que apegarse a cualquier conjunto de leyes, incluyendo las democráticas, será el mejor curso de acción practicable; pero, aparentemente, el apegarse a ellas debe incluir la necesidad de proscribir toda investigación que pudiera conducir a una demostración de que las leyes pudieran ser mejoradas. ${ }^{14}$ Pero en ese caso, era correcto que la democracia, en principio, ${ }^{15}$ se deshiciera de Sócrates; y de hecho está bastante claro que el pasaje referido equivale a recordar su ejecución. ${ }^{16} \mathrm{Si}$ abrigamos alguna duda al respecto, necesitamos

12 Véase especialmente 300c1-3 (en la traducción de Waterfield): "Y por esto, cuando las leyes y los estatutos han sido establecidos [...] el segundo mejor rumbo [second-best course] es impedir que cualquier individuo o grupo de personas jamás los infrinja en absoluto".

13 299c4-6.

14 299b-e forma el clímax de un pasaje que describe las consecuencias de una forma de gobierno apegada con rigor absoluto a las leyes establecidas; 300a, sin embargo, declara que tener oficiales del Estado que violen las leyes sin pensarlo dos veces, debido a que han sido sobornados o porque deben algún favor personal, sería, con mucho, peor; tenemos además el pasaje 300c1-3, citado arriba (nota 12). Es razonable, así, dada la expresión "y por esto" (dia tauta) en 300c1, suponer que el Visitante de Elea está defendiendo el respeto absoluto a la ley a pesar de las terribles consecuencias descritas en el pasaje que culmina con, e incluye, 299e. "Impedir que cualquier individuo [...] jamás viole [las leyes] en absoluto" evidentemente incluirá, si es necesario, "imponer las penas más extremas" a quienes indaguen la verdad acerca de las cosas, sobre la base de que podría resultar que la ley es, en algún aspecto, menos buena de lo que pudiera ser.

${ }^{15}$ Enfatizo "en principio": lo que el Visitante de Elea sugiere es que, si es cierto, como sugiere Sócrates el Joven, que apegarse a las tradiciones legales existentes propias es lo mejor que puede hacerse, entonces también será verdad que uno tendrá que eliminar a personas como Sócrates. Ya que Atenas de hecho mató a Sócrates en 399 a. C., la implicación es quizás que la ciudad estaba obrando según el principio de Sócrates el Joven; y sin duda ese principio hubiera sido aceptado ampliamente. Si los motivos de la ejecución fueron en realidad diferentes, tanto peor para Atenas y sus jueces. Véase más adelante.

${ }^{16}$ Cualquier investigador debe ser llamado "un observador de estrellas (meteôrologos), 
tan sólo pensar en aquel famoso pasaje del Gorgias ${ }^{17}$ donde Sócrates afirma que él mismo es el único estadista verdadero, o experto en el "arte de gobernar", sobre la base de que él era el único que se ocupaba en decir la verdad a la gente, en vez de lo que ésta quería oír. Si alguno pudiera parecer "más sabio que la ley", ése tenía que ser Sócrates, incluso a pesar de su persistente pretensión de no saber nada -y en ese pasaje del Gorgias, en efecto, lo dice él mismo. Pero entonces -y éste es el punto central de mi objeción-si Platón realmente está dispuesto a considerar la idea de que la democracia tenía justificación para matar a Sócrates, con seguridad habrá abandonado todo aquello que Sócrates pareció siempre representar y defender - no sólo la idea de la libre búsqueda, sino también su objetivo principal, aquello por lo cual esa búsqueda siempre pareció realizarse, a saber, la meta de una vida mejor y más virtuosa. Esto debe ser así, porque en cualquier caso las leyes para las que se requeriría obediencia rigurosa serían imperfectas, y habrían sido conformadas con unos fines que no sólo son diferentes de los fines de la ciudad virtuosa, sino de hecho incompatibles con ellos (por haber sido forjadas por personas carentes de conocimiento experto). ${ }^{18}$ En pocas palabras, si se nos pide que nos comprometamos a una obediencia absoluta de la ley, bajo los términos especificados, se nos está pidiendo también que aprobemos el asesinato de Sócrates. Así que mi pregunta es: ¿podemos realmente suponer que Platón fuera tan pródigo con sus principios? (y en tal caso, ¿cuáles serían las consecuencias para nuestra valoración acerca de él?)

Creo, sin embargo, que esta lectura del Político está radicalmente equivocada, y que la condena platónica de la democracia populista ${ }^{19}$ es tan vigorosa y completa como siempre. A fortiori, la democracia ateniense no tiene perdón por haber matado a Sócrates. Para demostrar mi tesis, necesito primero proporcionar más del contexto en el Político.

La parte del diálogo que me concierne inmediatamente va de 297c a 302b. El "Extranjero" o Visitante eleático se encuentra en camino de demostrar la afirmación de que todos los políticos existentes son meros imposto-

un sofista balbuciente (adoleschên tina sophistên)", y ser procesado "por corromper a otros más jóvenes" (299b7-8).

$17521 \mathrm{~d}$.

${ }^{18}$ Desde luego que podría ocurrir que una ciudad hiciera todo de manera enteramente correcta por accidente, o por gracia divina; pero si Platón alguna vez admite esta posibilidad, es sólo para tratarla con ironía (me refiero aquí al caso de los "buenos" políticos, discutido al final del Menón).

${ }^{19}$ Añado "populista" para excluir cualquier aspecto de la ciudad de las Leyes que pudiera ser considerado democrático; sin importar qué más sea, Magnesia no es gobernada según principios "populistas". Para la función de la asamblea en Estados sujetos por la ley (de hecho oligárquicos lo mismo que democráticos), véase Político, 298c y ss. 
res, que invaden el espacio que corresponde en propiedad al verdadero estadista o rey. Si puede mostrar esto, entonces dispondrá de una justificación para distinguir lo que aquellos hacen del verdadero arte del estadista, igual que ha separado previamente toda suerte de otras actividades (la crianza de cerdos, la fabricación de armas, etcétera). Sócrates el Joven, en 293e, se opone a la sugerencia, hecha por el Visitante, de que el rey ideal no se someterá a sí mismo al poder de la ley. Mi pasaje forma parte de la respuesta del Visitante a dicha objeción, la cual es obviamente crucial. Si la ley ha de ser soberana, ello permitiría que otras formas de constitución, y otras clases de político, vuelvan a ser consideradas junto con las mejores, dado que el conocimiento ya no sería un requisito absoluto del buen gobierno, como ha sostenido el Visitante. En el curso de su respuesta, ha mantenido que las constituciones no ideales son meras imitaciones de la mejor constitución, unas "para bien", otras "para mal";20 es esto lo que ahora explica a Sócrates el Joven. (Por supuesto, si las constituciones son, ellas mismas, meras "imitaciones", entonces aquellos que las ejercen serán "imitadores" -y de esta manera serán los impostores que él dijo que son.)

Su estrategia básica es, en primer lugar, sugerir que el principio que la gente suele recomendar, el de apegarse estrictamente a la ley establecida, es inteligible, pero en sí mismo absurdo como manera de dirigir un Estado. Sólo considérese, dice él, cómo serían la medicina o la navegación si obraran conforme a los mismos principios: provistas de reglas establecidas para ellas en una asamblea, por consejo de cualquier fuente, y aun de todas; con oficiales que supervisen a quienes resulten electos de entre el conjunto de los ciudadanos; con auditorías anuales a los oficiales, para asegurarse de que se atuvieron estrictamente a las leyes durante el periodo de su encargo; y con la indagación e investigación de la salud o el clima consideradas como un delito capital. ${ }^{21}$ Por otra parte, tener oficiales -ya sea en esta situación imaginada, o en la ciudad- que actúen sin ninguna consideración de las leyes, y por sus propios motivos personales, sería muchísimo peor.

Esta última sugerencia, en $300 a$, junto con su secuela, es -como hemos visto- lo que forma la base de la usual interpretación moderna del Político, como si anunciara una reconciliación con la democracia y con "la realidad". Ahora quiero presentar un trozo, más bien grande, del texto de 300a, primero en la traducción de J. B. Skemp, con la modificación de Martin Ostwald: ${ }^{22}$

$20293 \mathrm{e}, 297 \mathrm{c}$.

21299 c, con 297 e.

22 J. B. Skemp, trad., Plato's Statesman. Ed. e introd. de M. Ostwald. Indianápolis, 1992. Empleo esta traducción porque ella y/o la versión original de Skemp ha sido sin duda la más ampliamente utilizada desde su aparición en 1952. Si no ha contribuido a formar el consenso, en cualquier caso ha sido parte de éste. 
300a EXTRANJERO: Sí, pero hay una posible degradación más que considerar. Supón que obliguemos a cada una de estas artes a funcionar conforme a un código escrito y que pongamos a un magistrado a cargo de este código, ya sea por elección o por lo que determine el azar. Supón además que él no toma en cuenta el código escrito y, por motivos de provecho personal y favoritismo, emprende un curso de acción contrario a la ley, sin conocimiento alguno. Aunque el Estado anterior era malo, ¿no será este último aún peor?

SÓCRATES EL JOVEN: Ciertamente lo será.

300b EXTRANJERO: Las leyes que han sido establecidas representan el fruto de una larga experiencia -hay que admitir eso. Cada una de ellas incorpora el astuto consejo de algún asesor que ha persuadido a la asamblea del pueblo a llevarla a la práctica. Cualquier hombre que ose infringir estas leyes con sus actos es culpable de un error muchísimo mayor que aquel otro, el cometido por el rigor de las leyes, puesto que tal transgresión, de ser tolerada, pervertiría cualquier actividad bien organizada aún más que [lo que la pervierte] un código escrito.

SÓCRATES EL JOVEN: Sí, claro que lo haría.

300c EXTRANJERO: Entonces, en tanto los hombres decreten leyes y códigos escritos para gobernar cualquier campo de la vida, nuestro segundo mejor método de gobierno es prohibir que cualquier individuo o grupo lleven a cabo cualquier acto que los contravenga.

SÓCRATES EL JOVEN: Es verdad.

EXTRANJERO: Entonces las leyes parecerían ser copias escritas de la verdad científica en los diferentes terrenos de la vida a que refieren, copias basadas, tanto como sea posible, en las instrucciones recibidas de quienes realmente poseen la verdad científica acerca de estos asuntos.

SÓCRATES EL JOVEN: Sí, por supuesto.

EXTRANJERO: Y sin embargo nunca debemos perder de vista la verdad que ya expresamos antes. El hombre que posee conocimiento genuino, el auténtico estadista, permitirá en muchas ocasiones que sus actos sean dictados por su arte, sin prestar atención a preceptos escritos. Obrará así siempre que esté convencido de que hay otras medidas que [300d] son mejores que las instrucciones que antes escribió y envió a otras personas, en un momento en que él no podía estar ahí para controlarlas personalmente. ${ }^{23}$

SÓCRATES El JOVEn: Sí, eso fue lo que dijimos.

23 Véase 294 c y ss. 
EXTRANJERO: Así que cualquier individuo o cualquier grupo que posean un código de leyes, pero intenten introducir en éstas algún cambio, debido a que lo consideran una mejora, estarán haciendo lo mismo, según su propio parecer, que el auténtico estadista.

SÓCRATES EL JOVEN: Sí.

EXTRANJERO: Pero si actuasen de este modo, sin que sus mentes hayan sido iluminadas por el conocimiento, tratarían sin duda de copiar el original verdadero, pero lo copiarían muy mal. ${ }^{24} \mathrm{Si}$, en cambio, poseyeran [300e] conocimiento científico, no estarían ya, en absoluto, copiando, sino que ésta sería la verdad real y original de que estamos hablando.

SÓCRATES EL JOVEN: Ciertamente.

EXTRANJERO: Ahora bien: ha sido argumentado antes, y hemos convenido que ningún grupo grande de hombres es capaz de adquirir ningún arte, sea el que fuere.

SÓCRATES EL JOVEN: Ésa es la conclusión que hemos convenido.

EXTRANJERO: Concedido entonces que existe un real arte de gobernar [basilikê tis technê], ${ }^{*}$ real ni el grupo de los ricos ni el conjunto entero de los ciudadanos podrían nunca ser capaces de adquirir esta ciencia de la política.

SÓCRATES EL JOVEN: ¿Cómo podrían adquirirla?

EXTRANJERO: Parece seguirse de esto que hay un precepto invariable que estas constituciones imitativas [tas toiautas... politeias] tienen que obedecer, si pretenden reproducir, [301a] en la medida de sus posibilidades, esa única constitución verdadera, ${ }^{25}$ que es el gobierno del único estadista genuino que emplea la auténtica ciencia del Estado. Todo el mundo debe acatar estrictamente las leyes, una vez que éstas hayan sido establecidas, y nunca transgredir ni los ordenamientos escritos ni las costumbres ancestrales establecidas.

Las líneas cruciales aparecen en cursivas. Cualquier lector de esta versión del texto de Platón supondría razonablemente: a) que el Extranjero estaba legitimando la ley existente, sobre la base siguiente: b) que es producto de la experiencia, el astuto consejo, y la aprobación por parte de la opinión pública; c) que las leyes existentes son "copias de la verdad científi-

${ }^{24}$ Esto es lo que llamaré una "mala imitación" de la mejor constitución.

* N. del trad. La versión inglesa de Skemp tiene aquí "an art of kingly rule". En la traducción al español se añade la transliteración de la frase griega original, para evitar inducir al lector del texto en castellano a la confusión del adjetivo "real" (de realeza) con su homónimo "real" (de realidad).

${ }^{25}$ Produciendo así una "buena imitación". 
ca"; d) que las personas o ciudades que traten de cambiar la ley en ausencia del "conocimiento científico" posiblemente acabarán por tener malas leyes ("malas imitaciones"); y e) que las ciudades imitarán bien la mejor constitución siempre y cuando se apeguen a sus leyes existentes (precisamente en la medida en que estas leyes serán "copias" de las que prevalecerían bajo la mejor constitución). Detalles más o menos, esto es lo que uno obtendría de cualquiera de las traducciones del diálogo que he podido consultar; y también está reflejado con fidelidad en la mayor parte de la literatura secundaria acerca del Político, lo mismo que en las historias de la filosofía política. He citado la lectura que Sabine hace del pasaje; la de George Klosko ${ }^{26}$ es muy semejante. Otros ejemplos:

1) Pero las cosas conducirían a una confusión todavía más grave, si los hombres designados por esos ordenamientos los desatendieran, no en interés de la ciencia, sino en favor de sus propios deseos privados. Pues las leyes tienen siquiera alguna base en la experiencia y el consejo razonable. De aquí que, si se hacen leyes, es mejor-aunque mejor sólo en segundo lugar- que sean aplicadas. ${ }^{27}$

2) El Extranjero explica: Las leyes escritas aceptadas, sin importar cuál pueda ser su insuficiencia, se basan en una buena cantidad de experiencia y en el consejo dado de buena fe; el intento de violarlas conduce a una deficiencia muchísimo mayor [...] Estas leyes, escritas por hombres que conocen tanto como pueden conocer, en todo caso no contienen más que imitaciones de la verdad $[\ldots]^{28}$

3) Se puede estar seguro de que la "experiencia" es una base inferior a la epistêmê, y de que la necesidad de "complacer" y "convencer" a la muchedumbre es exactamente lo que el Extranjero denunció antes como "ridículo". Su adverbio hekasta, además, sugiere el carácter parcial de la reforma genuina. Por otra parte, el aspecto negativo de estas características se vuelve positivo cuando el Estado con leyes* es comparado con el abuso de la ley. La "mucha experiencia" es muy superior a la poca experiencia de un grupo o un individuo; y sin importar cuánto mayor sea el número de los demás, los pocos consejeros competentes efectivamente dan a la muchedumbre

${ }^{26}$ George Klosko, The Development of Plato's Political Theory. NuevaYork, 1986.

${ }^{27}$ L. Campbell, The Sophistes and Politicus of Plato. Oxford, 1867 (sumario añadido al texto de 300a-b).

${ }^{28}$ J. Klein, Plato's Trilogy. Theaetetus, the Sophist and the Statesman. Chicago, 1977, pp. 189-90.

* N. del trad., law-state: Estado de derecho. 
acceso a alguna comprensión [...] El sentido negativo de la noción de "imitación" [del Extranjero] está claro de antemano: los gobernantes que carecen de epistêmê política son una especie de facsímiles, y no la realidad auténtica que pretenden ser. La comparación entre el Estado con leyes y el abuso de las leyes, sin embargo, revela igualmente un sentido positivo. Justo en la medida en que sus leyes se basan en, o reflejan, la comprensión y el consejo de "hombres sapientes" (para tôn eidotôn, 300c), el Estado con leyes será como la comunidad del verdadero estadista, pareciéndose a ella como una especie de copia. $^{29}$

4) El régimen del que se dice que tiene buenas leyes es una mejor imitación del verdadero régimen, comparado con aquellos que son imitaciones relativamente deficientes e imitan el mejor régimen "para mal" (293d8-e5). ${ }^{30}$

La única voz discrepante de este siglo que he encontrado es la de G. R. Morrow; ${ }^{31}$ de entre las voces del siglo pasado, la de Grote ${ }^{32}$ (si hay otros, ${ }^{33}$ como puede muy bien ocurrir, al menos lo que he descrito es la visión que predomina en el periodo moderno).

Ahora bien, por mucho tiempo me preocupó que Platón hubiera empleado tanto espacio y energía -en la larga sección inmediatamente antes de 300 a (como Miller, por ejemplo, lo señala)-atacando los métodos vigentes de legislación, por absurdos y por propensos a no producir otra cosa que incongruencias, sólo para luego volverse y decir: "Bueno, cuando menos las leyes establecidas se basan en la experiencia, en el buen consejo y la persuasión, así que son aceptables/tolerables; son preferibles, en todo caso, a permitir que los individuos obren como les plazca". Me molestaba en particular que, habiendo identificado las leyes existentes como derivadas de algún tipo de juego de manos, pasara luego directamente a afirmar que ellas son, de algún modo, "copias de la verdad original”: ¿cómo? ¿Cómo pudieron

${ }^{29}$ M. H. Miller, Jr., The Philosopher in Plato's Statesman. The Hague, 1980, p. 100.

${ }^{30}$ H. R. Scodel, Diairesis and Myth in Plato's Statesman (Hypomneumata 85). Gotinga, 1987, p. 154. Véase también C. Griswold, "Politikê epistêmê in Plato's Statesman", en Anton y Preus, eds., Essays in Ancient Greek Philosophy, vol III. Albany, 1989, pp. 141-167; y Annas y Waterfield (vid. supra, nota 11).

${ }^{31}$ G. R. Morrow, Plato's Cretan City. Princeton, 1960, p. ej., p. 585.

${ }^{32} \mathrm{G}$. Grote, Plato and the Other Companions of Socrates, 2a. ed. Londres, 1888, pp. 267 y ss.

${ }^{33}$ G. R. F. Ferrari, "Myth and Conservatism in Plato's Statesman", en Reading the Statesman (vid. supra, nota 3), 389-97, en cualquier caso, propone una perspectiva no estándar y sutil. 
los consejeros de las asambleas, o las asambleas mismas, obtener acceso a la "verdad original"? Debiéramos notar en especial el giro que va de "algún consejero", en 300a, a "las instrucciones recibidas de aquellos quienes realmente poseen la verdad científica acerca de estos asuntos", sólo unas pocas líneas después: ¿đe dónde sacó el "consejero" sus instrucciones? Pero quizás todos los demás intérpretes han percibido la misma dificultad. La única explicación pudiera ser una confusión de buena fe por parte de Platón, ya sea acerca del meollo de lo que quería decir, o respecto de la manera que eligió para expresarlo.

Sin embargo, cuando llegué a hacer mi propia traducción, ${ }^{34}$ me di cuenta de que la lengua griega no nos obliga, en modo alguno, a entender así el pasaje. El resultado fue el siguiente:

300a Visitante: ¿Pero qué hay de la siguiente consideración? Si forzáramos a cada una de las cosas mencionadas a ser practicada de acuerdo con reglas escritas, y [obligásemos] a la persona electa o nombrada para desempeñar un cargo por sorteo, con base en el azar, a supervisar estas reglas escritas nuestras; pero esta persona no prestara ninguna atención a lo escrito, ya sea por obtener provecho de algún modo, o para otorgar algún favor personal, [a5] y se propusiera hacer cosas distintas, contrarias a éstas, no sabiendo nada [mêden gignôskôn], ¿no sería éste un mal aún mayor que el anterior?

SÓCRATES EL JOVEN: Sí, muy cierto.

300b VISITANTE: Sí, puesto que, según creo, si alguien se atreviera a actuar contra las leyes (que han sido establecidas a base de mucho intentarlo, habiendo dado estos o aquellos asesores su consejo acerca de cada asunto en forma atractiva, y habiendo persuadido a la mayoría de aprobarlas), éste cometería un error muchas veces mayor que aquel otro, [b5] y subvertiría toda actividad experta en un grado aún mayor que las reglas escritas.

SÓCRATES: Sí - ¿Cómo podría no hacerlo?

300c VISITANTE: Entonces, por estas razones, el segundo mejor modo de proceder, para quienes establecen leyes y reglas escritas acerca de cualquier cosa, es no permitir que ningún individuo o grupo hagan jamás algo contrario a éstas, ninguna cosa en absoluto.

SÓCRATES: Correcto.

c5 VISITANTE: Las imitaciones de la verdad de todas y cada una de las cosas serían éstas, ¿no es así? Es decir, aquellas cosas que

${ }^{34}$ C. J. Rowe, Plato: Statesman, con traducción y comentario. Warminster, 1995. 
vienen de quienes saben, las cuales han sido escritas hasta donde ello es posible.

SÓCRATES: Desde luego.

VISITANTE: Ahora bien, dijimos -si recordamos bien- que quien posee conocimiento [ton eidota], aquel que en realidad posee el arte del estadista, hará muchas cosas con su saber [technêi], relativamente a su propia actividad, sin tomar en cuenta las leyes escritas, cuando otras cosas le parezcan mejores, [300d] contra las cosas escritas por él mismo y dadas en calidad de órdenes a ciertas personas que no están entonces con él.

SÓCRATES: Sí, eso es lo que dijimos.

VISITANTE: Y bien, [si] un individuo cualquiera, o cualquier conjunto grande de personas, para quienes [d5] se han establecido leyes escritas, se proponen hacer cualquier cosa que sea distinta o contraria a aquéllas, sobre la base de que [esto otro] es mejor, hacen lo mismo, hasta donde pueden, que aquel experto genuino ¿no es así?

SÓCRATES: Absolutamente.

VISITANTE: Así pues, si hicieran tal cosa siendo carentes de conocimiento [anepistêmones ontes], tratarían de imitar lo que es verdadero, pero lo imitarían [300e] de manera por completo deficiente; ¿y si, en cambio, proceden siendo dueños del saber [entechnoi], esto no es una imitación, sino esa cosa misma que es con suprema verdad aquello que se propone ser?

SÓCRATES: Creo que estoy completamente de acuerdo.

VISITANTE: Pero entre nosotros se ha establecido como un acuerdo -lo convinimos antes, en cualquier caso- que ningún conjunto grande de personas [e5] es capaz de adquirir jamás ningún tipo de saber [téchne].

SÓCRATES: Sí, ése sigue siendo nuestro acuerdo.

VISITANTE: Entonces, si existe algún real saber [basilikê tis technê], ${ }^{*}$ el grupo constituido por los ricos, y el pueblo todo en su conjunto, no podrían adquirir jamás el conocimiento experto de la política [tên politikên tautên epistêmên].

SÓCRATES: ¿Cómo podrían adquirirlo?

VISITANTE: Entonces, según parece, lo que se requiere de todas las constituciones de esta clase, es que, si van a imitar [301a] bien, hasta donde puedan, aquella constitución verdadera de un solo hombre que gobierna con conocimiento [meta technês archontos],

*N. del trad. La versión inglesa de Rowe tiene aquí "some kind of kingly expertise". 
no deben nunca -dado que tienen sus leyes-hacer nada que sea contrario a lo que está escrito y a las costumbres ancestrales.

El Extranjero comienza por dar la mejor lectura posible de la legislación y los procesos legislativos existentes, pero ésta es una lectura que critica tanto cuanto alaba: la experiencia, al menos según el Gorgias, ha de ser distinguida del conocimiento experto; y es la calidad de los "consejeros" lo que importa sobre todo (por otra parte, como se nos ha dicho antes, la aceptación o rechazo por parte de los ciudadanos carece de pertinencia). ${ }^{35}$ Lo único que está claro hasta aquí es que haber establecido leyes y apegarse a ellas es mejor que permitir a los oficiales del Estado que actúen contrariamente a las leyes, según le parezca mejor a cada quien; pero, dado el origen de las leyes existentes, ésta sigue siendo una situación peligrosa. (Cuando Sócrates la llama lo "segundo mejor", lo que quiere decir es sólo que no es lo mejor en primer lugar, como la gente supone normalmente; es mejor solamente en segundo lugar de entre las tres alternativas que están en juego -mejor que la tercera, pero eso es todo.) ${ }^{36}$ Entonces, en c5-6 ("Las imitaciones de la verdad..."), no se hace referencia a las leyes existentes; lo que está siendo enunciado es un principio general, el cual cubrirá, no todas las leyes, sino sólo aquellas que el estadista experto instituiría. Éstas son las "imitaciones de la verdad" (porque éstas son las únicas leyes en cuya formación habrán intervenido personas con conocimiento, eidotes). ${ }^{37}$ Debido a que el rey-legislador ideal posee conocimiento, no debemos insistir en que él se apegue a las leyes; puede cambiarlas cuando conciba algo mejor (c8-d2). Pero (d9-e2) si cualquier otro trata de hacer lo mismo, sin basarse en el conocimiento, los resultados serán por fuerza malos (excepto quizás por accidente), de manera que ésta será una mala imitación de lo mejor -es decir, la que resultará cuando quienes carecen de conocimiento imiten la práctica del estadista óptimo, de cambiar las leyes cuando él concibe algo mejor (porque, careciendo de conocimiento, éstos no pueden confiablemente concebir nada mejor, a diferencia de aquél).

El problema es entonces a cuánto equivale el valor de una buena imitación de lo mejor. El Visitante dice tan sólo "si [tales constituciones inferiores] van a imitar bien aquella constitución verdadera [...], no deben nunca

\footnotetext{
${ }^{35}$ Por ejemplo, 292a-c.

${ }^{36}$ Lo mejor en primer lugar es, desde luego, el Estado gobernado por el rey experto, con base en su conocimiento calificado.

37 David Sedley planteó la pregunta de si houtos (c5 tauta) pudiera ser visto adecuadamente como anticipatorio (éstas, a saber...); véase mi reseña de Annas y Waterfield (vid. supra, nota 11) en The Classical Review.
} 
-dado que tienen sus leyes- hacer nada contrario [a ellas]" (300e11-301a3). Esto es sin duda congruente con la respuesta usual, que la "buena imitación" significa reflejar, tanto como sea posible, las leyes del mejor Estado; pero esa interpretación parece depender enteramente del apoyo de 300b1-c7, y en especial de 300c5-7,38 el cual ya no está disponible -y en cualquier caso, seguiría siendo adecuado preguntar de qué manera, exactamente, podrían esas constituciones inferiores haber tenido acceso, o siquiera haberse aproximado, a las leyes de los mejores. En lugar de esto, yo propongo que imitar bien la mejor constitución significa simplemente acatar las leyes establecidas, que es lo que la mejor ciudad hará ella misma cuando se encuentre en la situación que siempre prevalece en las ciudades inferiores - a saber, cuando no está presente ninguna persona sabia e inteligente que muestre qué cambios deben hacerse. La distancia que puede separar a estas constituciones inferiores de la mejor constitución es con seguridad muy grande, en la medida en que sus leyes habrán de ser malas, con casi total certeza; y, de hecho, el Extranjero procede a expresar su sorpresa respecto de cuánto llegan a sobrevivir efectivamente las ciudades, no sólo las que dan la espalda a la tradición de sus leyes, sino las que no (301e-302b).

Según esta lectura, las leyes existentes no tendrán conexión alguna, excepto por accidente, con las leyes del Estado ideal; y por lo tanto, la dificultad principal de la interpretación tradicional -cómo habrían podido jamás las constituciones inferiores tener acceso al conocimiento, cuya carencia es lo que en realidad hace que sean lo que son- se desvanece. No es tanto el problema de si es o no viable el modo tradicional de traducir el pasaje, como traducción del griego; se trata más bien de lo que permite comprenderlo mejor, con la convicción de que debemos obediencia al principio hermenéutico de la caridad y de que debemos hacer lo mejor para con Platón, absteniéndonos de atribuirle inconsistencia o cualesquiera otros vicios reconocidos, a menos que sea absolutamente necesario.

Las consecuencias de la lectura que propongo son, pues, de gran magnitud. En este pasaje, Platón no está llamando la atención hacia una legitimación de ninguna forma de gobierno existente; más bien ocurre lo contrario. La democracia ateniense sigue estando firmemente proscrita. Lo que es más, no puede hacer absolutamente nada para redimirse a sí misma; encara sólo dos alternativas, de las cuales una es simplemente menos vulnerable que la otra: o bien, debe fijarse a sí misma con rigidez, o bien, debe permitir (¿seguir permitiendo?) la desobediencia de las leyes. La actitud de Platón parece ser exactamente la que él representa (¿al menos la mayor parte del tiempo?)

\footnotetext{
${ }^{38}$ Es decir, de 300c5-7 entendido como una afirmación de que las leyes existentes son "imitaciones de la verdad".
} 
en el Sócrates de la República, a saber, que según la perspectiva más ascética, el único camino verdadero hacia adelante, la única ruta que nos daría una ciudad de la que podríamos estar realmente orgullosos, sería borrar lo escrito y comenzar de nuevo -y esto no debiera sorprendernos, ya que en lo que concierne a Platón, el propósito del arte del estadista, o arte de la política, y por lo tanto, el de la ciudad o el Estado que este arte gobierna, es el mejoramiento de las almas de los ciudadanos. Ninguna de las formas acreditadas de constitución tiene en realidad ese propósito; y si alguna de ellas, per impossibile, lo adquiriera junto con el medio de lograrlo efectivamente (es decir, el conocimiento), en realidad se habría hecho idéntica a la mejor constitución.

La siguiente consecuencia es que lo "segundo mejor" del Político no es lo mismo que lo "segundo mejor" de las Leyes. En el Político, el Extranjero argumenta contra la tesis de que apegarse a las leyes establecidas es la primera y mejor opción para las ciudades-Estados; no es así, dice él -lo mejor es una ciudad fundada en el conocimiento. Llevar en concreto a la práctica las leyes de una ciudad -tales como son- es lo mejor sólo en segundo lugar, y, para el caso, un segundo lugar bastante malo. En contraste, lo "segundo mejor" de las Leyes es una ciudad que, aunque carece del gobernante ideal, posee un cuerpo de leyes que derivan al menos en parte de la reflexión filosófica, lo cual es mucho más parecido a lo que el Político quiere decir con una "imitación de la verdad" (y de hecho se toman provisiones en la constitución imaginaria para cambiar las leyes, cuando surja alguna posibilidad de mejoría: evidentemente, en ese caso, en los términos del argumento del Político, hay en realidad conocimiento en Magnesia). Podemos entonces preguntar con razón cuánto habrá cambiado de veras desde la $R \boldsymbol{e}$ pública, y mi propia respuesta es: extremadamente poco. Tampoco hay muchas pruebas de ninguna reconciliación en las Leyes con lo que los atenienses de ese tiempo hubieran llamado democracia. Ahí, el Ateniense principia escogiendo al cuerpo ciudadano, de modo que ser ciudadano de Magnesia no es algo que dependa del nacimiento, sino de que uno sea, como podría decirse, una persona de calidad; mientras que en la democracia ateniense, la calidad, lejos de ser un requisito de la ciudadanía, en realidad derivaba de ésta. "Democracia" en las Leyes significa meramente el involucramiento en el gobierno cotidiano y el control de éste, según la ley, por los 5040 ciudadanos varones.

No es difícil ver el atractivo que tiene para la mente moderna un Platón recién democratizado, quien por fin comienza a entender razones después de los excesos de la República. Platón es, después de todo, una de las grandes inteligencias de la Antigüedad, si no es que la mayor. Si se convirtió siquiera en un casi-demócrata renuente, eso podría hacer un poco más fácil que nos 
agradara. Ocurre algo semejante con las otras versiones de la lectura desarrollista: todas nos permiten darle alguna forma satisfactoria a un cuerpo de materiales difíciles. Y sin embargo, no está claro que el Platón de la República sea en realidad menos "pesimista", o menos realista o constitucionalista que el Platón de las Leyes. Todo depende de qué clase de obra pensamos que es la República, y en particular, si pensamos que contiene un conjunto de propuestas políticas concretas - esto es, algo así como el anteproyecto arquitectónico para su implementación (jseguro que no!)- o si, por ejemplo, primero pensamos en ella como una obra de reflexión crítica, o como una especie de experimento del pensamiento; cada uno de estos tipos de enfoque, o ambos juntos, me parecen eminentemente defendibles.

Y entonces, podemos rechazar la sugerencia de Sabine de que, en el Político, Platón "observa que ahora la ejecución de Sócrates tiene que justificarse" (en realidad, Platón nunca se refirió a nada tan explícito como una "observación”). El punto es que tendría justificación si la regla de fijeza absoluta de las leyes pudiera justificarse, pero de hecho, como lo aclara el Extranjero, esa regla no puede ser correcta. Lo que él dice a su público es: "Si creen que lo mejor es apegarse a sus leyes existentes (lo cual es un curso racional de acción, al menos en la medida en que cambiar las leyes exigiría un conocimiento del que ustedes mismos carecen), la consecuencia es una situación que les exigirá hacer cosas absurdas, incluyendo matar a personas como Sócrates. Pero eso fue lo que de hecho hicieron ustedes, matar a Sócrates; por lo que ahora están en una posición absurda, con sus democracias, y sus oligarquías".

Varias cuestiones comienzan a surgir en este punto, de entre las cuales destacan dos: la que concierne a la naturaleza y el sentido íntegros de la filosofía política platónica, y la de si Platón tiene alguna clase de remedio viable que ofrecer junto con su escalofriante diagnóstico de la realidad política contemporánea. ${ }^{39}$ Pero mi interés principal en este artículo ha sido más limitado: describir un caso notable de un fenómeno familiar, a saber, nuestra capacidad de encontrar en un texto exactamente lo que esperamos encontrar, a pesar de todas las pruebas de que en realidad ello no se encuentra ahí. Mi conclusión inmediata es que el desarrollismo (o, formulado de un modo más amplio, la aproximación biográfica) es un instrumento peligroso, y que existen otros instrumentos que debieran ser desplegados antes - por ejem-

${ }^{39}$ Que posee un remedio no es dudoso (véase las Leyes); que sea "viable" o no, es, desde luego, otro asunto. Pero si nos preguntamos de nuevo por el para qué de las utopías de Platón, la postura es considerablemente menos vulnerable. (Vid. infra, en especial mi tesis de que Platón permanece, de manera fundamental, -a pesar de todas las apariencias- comprometido con el modelo socrático de la filosofía.) 
plo, una sensibilidad para con la argumentación, en su contexto entero, combinado con una dosis de caridad (si se requiere).

Una última cuestión, que me llevará de regreso a la otra parte del terreno donde comencé. Aunque Platón no llegó, después de todo, a aprobar la democracia por matar a Sócrates, todavía tenemos que enfrentar la acusación de Popper, de que, a pesar de todo, lo traicionó; o, alternativamente, que prefirió liquidarlo en silencio él mismo, en un acto de parricidio intelectual. Del cargo de ser antidemocrático, Platón es sin duda culpable, y a mucha honra (como he dicho, el sentido en que la ciudad de Magnesia es una "democracia” es mínimo). Pero entonces, según mi tesis, las credenciales democráticas de Sócrates mismo son bastante endebles. Podría ser una especie de "igualitarista", y podría suponer que él mismo y todos los ciudadanos tienen algún tipo de contrato, en virtud del cual deben obediencia a las leyes (democráticas) de la ciudad, pero a partir de los escasos datos con que contamos, Sócrates desconfiaba de la corrección del principio fundamental de la democracia ateniense, que "quienquiera puede hablar" en la asamblea. Por otra parte, y aquí es donde comienza mi defensa de Platón, el modelo socrático de la filosofía, como algo que se parece a (pero que no llega a ser) la libre indagación, permanece en el centro de su pensamiento hasta el final. Este modelo está contenido en el personaje de Sócrates que aparece en los diálogos, quien siempre representa al filósofo ideal, y especialmente a través de su aspecto de ignorante.

Este "siempre" será controvertible. Es una opinión muy común que, después de los diálogos "socráticos", Sócrates se vuelve cada vez más experto, más conocedor o sabedor, y que sus declaraciones de ignorancia con frecuencia suenan huecas; de esto, la prueba principal es la República. De manera aún más obvia, está el punto de Popper, de que los "Estados ideales" de Platón, ya sea en la República o en las Leyes, parecen no dejarle espacio a la búsqueda del conocimiento, libre de todo miedo, en privado, por parte del individuo. No dispongo ya de espacio para rebatir estos puntos como es debido y en forma completa. De cualquier modo, estoy convencido, por varias razones, de que esta interpretación tan común es errónea. En primer lugar, Sócrates continúa regresando -el Sócrates familiar, el Sócrates ignorante: está ahí, en la propia República, ${ }^{40}$ en el Teeteto, y luego en el Filebo, usualmente fechado justo antes de las Leyes, última obra de Platón. La segunda razón es que los diálogos representan con mayor frecuencia a la filosofía como investigación y búsqueda, como un conocimiento acerca de temas difíciles, y la describen en términos de la adquisición parcial de un conoci-

${ }^{40}$ Véase especialmente 506b-e. 
miento tal, mucho más que en términos del logro del saber total. La perspectiva predominante es la que Sócrates describe al final del Fedro, que la sabiduría, sophia, es cosa de dioses, y que lo máximo a que pueden aspirar los seres humanos es al amor de la sabiduría, es decir, a la philo-sophia. En tercer lugar, la tesis de los filósofos como conocedores más que como buscadores aparece - hasta donde alcanzo a ver por ahora- (casi) ${ }^{41}$ sólo en el contexto de las utopías políticas: esto es, en la República, el Político, y (más dudosamente) en las Leyes. La significación de este último hecho, si es que lo es, es que en ninguno de estos tres casos estamos tratando con el mundo tal como es en realidad; todos presuponen condiciones que, de hecho, no se dan. En cada caso, la pregunta es “¿como se vería el mundo si...? $\mathrm{Si}$, entre otras cosas, la filosofía hubiese hallado las respuestas a las preguntas por lo bueno, lo bello y lo justo, entonces deberíamos poseer lo que se supone creemos que sería la mejor clase de Estado o ciudad -lo cual, sin duda, tiene el propósito tanto de sugerirnos lo que está mal en nuestros actuales arreglos y, al menos de manera aproximada, el modo como pudiéramos corregir las cosas (esto es, en general, mediante la adopción de una perspectiva más racional). La proyección en este caso incluye una proyección de cómo se vería la filosofía misma en el mejor de todos los mundos imaginables - pero no necesariamente posibles. En general, podríamos decir que hay dos imágenes del filósofo en los diálogos: una, la imagen del filósofo tal como él es (y, haciendo a un lado el libro v de la República, siempre es un él), a tientas en el mundo real y cayendo en pozos, ${ }^{42}$ porque siempre tiene la cabeza en las nubes; y otra, la imagen del filósofo tal como podría ser en un mundo distinto, que él ha organizado conforme a su propia imagen, como él -ideal, pero imposiblemente- sería.

Queda en pie una objeción (aunque estoy seguro de que habrá otras): sigue siendo cierto que es difícil ver dónde podría proseguir el filosofar privado, no patrocinado por el Estado, en cualquiera de los "mejores Estados" de Platón. Hay una Academia oficial, que produce los futuros gobernantes, en la ciudad de la República, y hay un consejo intelectual-político* del gobierno nocturno en la ciudad de la Leyes, y estas instituciones satisfarían todas las necesidades filosóficas de la ciudad. Ya que, evidentemente, tendrían todas las respuestas (o, en el caso de las Leyes, quizás sólo una canti-

\footnotetext{
${ }^{41}$ De acuerdo con Symposio 204a, los sabios no filosofan. Este mismo diálogo parece contemplar la posibilidad de la adquisición de la sabiduría; y sin embargo está dominado por la figura de Sócrates, quien, como Eros, parece estar permanentemente suspendido entre sabiduría e ignorancia.

${ }^{42}$ Cf. Teeteto 174 a (Tales).

* N. del trad. La expresión que emplea Rowe es "think-tank", literalemente, un "tanque de pensamiento", una suerte de inteligentsia oficial.
} 
dad suficiente de ellas), se podría considerar que no tendría mucho caso que nadie más pensara. En la República, de hecho no habría nadie más que fuera capaz, en ningún caso, ya que todos los filósofos en potencia habrían sido tragados por la máquina del Estado. Pero mi impulso instintivo es negarme por completo a jugar juegos como éste: si estas ciudades son imaginarias, no le veo sentido a argumentar acerca de los detalles que Platón ha omitido incluir. (Él podría haber añadido: si la felicidad depende de la virtud, y la virtud plena depende del conocimiento, entonces desde luego que la filosofía sigue siendo un requisito primario para todo el mundo $-\mathrm{O}$, ya que, ciertamente, él no es un igualitarista, para todos los que son capaces de filosofar.)

Aquí es donde el punto acerca de la concepción de la filosofía de Platón otra vez se vuelve importante. Desde luego, cualquier ciudad o individuo que se hicieran sabios cesarían de ser filosóficos, si filosofía es buscar la sabiduría. Pero si ninguna ciudad o individuo pueden tornarse sabios, la cual considero es la postura de Platón, ése no es un asunto importante, excepto en la medida en que indica lo que ya habremos adivinado de antemano -que Platón es un platonista, quien piensa que existen verdades que pueden ser conocidas. Las excursiones intelectuales independientemente orientadas de un Sócrates seguirán siendo lo que, en un mundo real, todos necesitaremos; de modo paradójico, es este punto lo que, según creo, pretenden promover, de una manera indirecta, las ficciones platónicas de sociedades detenidas, congeladas.

Traducción al español de Enrique Hülsz*

* Dejo constancia aquí de mi agradecimiento a Nicole Ooms y a María Teresa Padilla, quienes amablemente revisaron la primera versión al español, y gracias a cuyas numerosas críticas y aportaciones la presente ganó en fidelidad al original en inglés y claridad en castellano. Los errores que subsistan caen, desde luego, exclusivamente bajo mi responsabilidad. 